\title{
TESL in the Developing English World
}

Chris Hawes

Education in many developing countries is in a state of crisis. Encumbered by economic stagnation, political instability and/or radical shifts in ideology, the problems facing many African and Asian countries, particularly the former British colonies, have quite understandably entered their classrooms. For the TESL or TEFL teacher working in such countries, problems of a national scope often translate into over-crowded classrooms, severely limited resources and little contact time. Moreover, recent policy changes in some countries have relegated English study to a position of secondary importance and by so doing undermine the efforts of even the most dedicated teachers. As to be expected, the standard of English in countries as far apart as Malaysia and Nigeria continues to fall from year to year as reflected in their school-leaving exams.

While the problems facing English study are country-specific, some common patterns have emerged which transcend the boundaries of any single country. In brief:

1. Economics. Countries which rely on single or limited commodity exports have been particularly hard hit over the last decade. Faced with declining GNPs, countries, especially those in West Africa, have had to redirect shrinking resources away from education. Smaller budgets lead to fierce competition between departments and in those cases where technical training or another language have been deemed national priorities this means that most schools cannot afford to reduce class size (usually 45 to 55 students), replace worn or out-dated texts or offer English teachers the materials needed to offer quality instruction. And with little in department budgets for immediate needs, in-service training or professional seminars and workshops remains nonexistent in all but a few countries. This helps to explain the preponderance of choral recitation and audiolingual drills as the sole techniques used over much of the world.

2. Counter-productive Policy Shifts. Since many former British colonies are politically fragile anomalies made up of competing ethnic groups, changes in power often herald radical shifts in educational policiespolicies that may reflect the aspirations of certain special interest groups. As Malaysia best illustrates, when a group gains control, it may try to consolidate its position by replacing English with its own language as the national medium of communication. If successfully implemented, as the 
ethnic Malays have done, English disappears as the medium of instruction in schools and becomes simply a foreign language to be studied for forty minutes a day. Not only does this make a quantitative change in contact time but its qualitative effect on student attitudes is even more deleterious as students no longer see the importance of learning English. Unfortunately for them, however, the performance criteria on school-leaving English exams is seldom recalibrated to reflect the language's new status.

Even when English is maintained as the language of instruction, other policies often hinder the opportunity for coordinating language instruction with the students' other subjects. Perhaps most problematic is the tendency of policy makers to treat English as a subject (in the classical sense) rather than as a foreign language to be learned for the purposes of communication. Many students, particularly those in West Africa, still study the English classics and parse sentences, even when they lack a rudimentary command of the language. Such a stance unfairly handicaps rural students who, unlike their urban counterparts, lack previous exposure to the language through television and print.

3. Professionalism. Educational policies are often shaped by the primacy of nation-wide or transnational school-leaving exams-exams that are questionable measures of language competence yet remain the pinnacle of achievement that all strive towards. The dilemma facing teachers is whether to teach some potentially useful language, building on what little the students already know, or else to cover exam-related topics in a belated attempt to ready students. Unfortunately, as many teachers are not trained in TESL, they usually choose the latter course since the limited materials available are typically aimed towards exam readiness. Even the trained TESL teacher is faced with the dilemma of whether to teach authentic language or to prepare students for an exam.

Here then lies another problem: a lack of professional expertise. Countries in both Africa and Asia often adopt a policy of placing graduates in any subject field where teachers are needed. In many schools this means that History, Math or Commerce majors are forced to teach English, the assumption being that language competence is the only prerequisite needed for teaching English. Until recently, Nigeria took this a step further and placed those students who failed Form 3 (Grade 9) into Teacher Training Colleges in preparation for having them teach elementary school. Although elementary school is conducted in the students' local vernacular, the teacher's responsibilities also include introducing junior students to English. This is an essential preparation since all classes in secondary school are conducted in English. Obviously those who have failed Form 3 may not be the most suitable candidates for teaching a foreign language. 
4. Uncritical Adoption of Western Methods. Counterproductive policies also encroach from an unsuspected quarter: the West. Local policy makers often adopt American or British approaches to education without adapting such approaches to local conditions. This can be as simple as adopting a country-wide school calendar which starts either in January or September in countries where climatic and seasonal variations are numerous-a situation that leads to high absenteeism during farming season.

The wholesale endorsement of certain Western methods is a more subtle but no less counterproductive example of such an influence. The recent introduction of a communicative syllabus in some Asian countries is a case in point. While the introduction of communicative language teaching can certainly be applauded over former methods, it cannot simply be transposed en masse onto a foreign context without serious deficiencies arising. Unfortunately, to a large extent that is what has happened: instead of engaging in mindless pattern drills, many rural Asian students are now learning the language appropriate for opening a bank account or applying for a driving licence-an equally mindless endeavour as few students will ever do either, and if they do, it will certainly be in a language other than English. Likewise, techniques germane to the communicative approach like information gap activities, paired practice and shared group work are not succeeding as intended simply because students find it difficult not to succumb to the urge to use their shared native language. Perhaps with a little creative forethought such techniques could be adopted. However, that and modification is exactly what is all too often missing: creative forethought.

6. Attitudinal Changes. For teachers and students alike, the study of English is often marked by frustration, boredom and resentment. For teachers, especially those trained in other subjects, teaching two hundred or more students a day according to a syllabus that is beyond the ability of all but a few, English class is an imposition forced on them. For students studying in countries where English is no longer the national language, English is often seen as an incomprehensible waste of time with no personal use. For students studying in countries where English is still maintained as the medium of instruction, English study is all too often an agonizing, frightful experience marked by repeated failure and teacher ridicule. In both cases, the demands placed on teachers and students are too taxing, the rewards too few, and the paucity of excitement either through interesting materials or varied methods too limited to motivate or stimulate either group. Of course, such attitudes occur and are to a large extent determined by a context, whether economic or ideological, which provides little encouragement for those who wish to teach or learn English. 


\section{Conclusion}

In effect, developing countries often pay lip service to the importance of English study yet do little in the way of creating the necessary environment needed to ensure success. So long as countries are unwilling to devote the necessary professional resources needed to help and encourage students while setting unrealistic goals for them, failure and frustration will continue to mark many a student's encounter with the English language. In terms of what Canadian professionals can do to influence foreign policy, our contribution or even our opportunity to contribute will sadly remain small and limited. There are, however, two significant areas where we may be able to exert an influence.

First, development aid organizations such as CUSO and CIDA should continue to place trained EFL teachers overseas. Such teachers are needed not only in the classrooms but more importantly they are a resource for their host-national colleagues, especially in situations where teacherupgrading programmes have been implemented. In Nigeria, for example, CUSO helped to develop a teacher-upgrading programme that not only introduced contemporary ESL/EFL methods to many teachers and produced a variety of useful materials, but also set up a system where local teachers and other professionals could share and pool their resources.

The second area where Canadians may be able to help is when overseas teachers come to Canada to continue their studies. Each year a significant number of foreign teachers enrol in ESL/EFL programmes at our universities, particularly at the post-graduate level. Unfortunately, such programmes are usually oriented towards language teaching within a Canadian context. What is needed is programmes that are developed with the foreign teacher and EFL in mind-programmes that are sensitive to the realities these teachers face. This of course is no easy task, and calls for both research and networking between universities and professional organizations both here and abroad. But given the enormity of the problems facing these teachers, along with our commitment to professionalism, these steps must be taken if we are to increase our contribution to ESL beyond our borders.

\section{THE AUTHOR}

Chris Hawes is an ESL teacher who has worked around the world. For the last six years he has worked for CUSO in both Nigeria and Malaysia, both as a classroom teacher and as a Special Programme Assistant for a teacher-upgrading programme. 